\title{
DYNAMICS OF THE CREATIVE INTERPRETATION IN EARLY CHILDHOOD COMMUNICATION WITH ART IN A MUSEUM ENVIRONMENT \\ Any Zlateva ${ }^{1}$, Katya Tineva-Gyurkovska ${ }^{2}$
}

\begin{abstract}
:
Introduction: The research paper tracks the changes in the regular development of the way children perceive visual arts. It views the dynamics of the creative interpretation of children at the pre-school age when directly communicating with pieces of art in a museum environment. An important stage of this study is related to the role of the informal gallery environment, which suggests an intense visual stimulation and reinforces children's desire to actively take part in it. This imposes the application of specific integrated pedagogical approaches and methods, close to museum pedagogy and visual arts education.

Purpose of the study: The research aims at tracing some of the main processes pertaining to the dynamics of the visual reaction of children of 6 to 7 years of age when directly communicating with visual arts and their level of creative interpretation in the process of drawing afterwards.

Methods: For achieving the aims of the research we used some interdisciplinary methods. In the theoretical part we present some of the fundamental works on the subject. We emphasize the methods that integrate the history of art and pedagogy, which include: the description of the paintings with elements of formalism is the study of art and analysis of the visual reaction when communicating with pieces of art. This description should be adapted to the age of the children and some empirical and proximity pedagogical methods for evaluating the achieved results.

Findings and results: In the first part of the research the accent is put on the different levels of reaction children have at the age of 6-7, regarding the recognition of separate compositional elements, objects, colours, forms, seasons, hours of the day, finding out emotional conditions and other important elements of composition sings in the observed pieces of art.

In the second part we show the results and we systematize and analyze children's free creative modulations. They concern different aspects of the visual stimulation and the following creative interpretation through the art activity of children at the age of 6-7. We observed the correlation between the drawings of the children and the perceived pieces of art, as a consequence of the stimulation of their visual perceptions and views. We analyzed the influence of a museum environment on children's graphic, colourful and emotional expression through drawing.

Conclusion: The summary and conclusion of the research provide the basis for development and optimization the methodological-pedagogical system of working with children in a formal and informal environment.
\end{abstract}

UDC classification number: 374, DOI: 10.12955/cbup.v7.1441

Keywords: art education, creative interpretation in early childhood, visual reaction, communication with art

\section{Introduction}

The focus of this research paper is directed towards analysing some pedagogical and psychological processes related to existing opportunities for communication and creative interpretation of pieces of art in a museum environment at an early childhood age.

Two key aspects for studying the visual reaction are reviewed in a brief theoretical and empiric plan. One of them concerns direct communication with art and the ability to comprehend it, whereas the other tracks and analyses the dynamics of the creative process of children following their interaction with works of art.

The focal point in the paper is the presentation of the connection between the different research stages. At the beginning we followed the level of visual stimulation and reaction through viewing pieces of art that belong to one genre of painting. The next step included the research of the subsequent impact that stimulation had on the individual creative interpretation of children 6 to7 years of age.

What needs to be emphasized is the role of the informal gallery environment for the achieved results because it suggests much more intense visual stimulation and reinforces the desire for the interactive inclusion of children in the pedagogical process.

The research has an interdisciplinary dimension which requires the application of specific integrated pedagogical methods and approaches, closely related to the museum pedagogy and the pedagogy of art education.

To follow some main pedagogical and psychological processes connected with the dynamics of visual reaction of children at the age of 6-7 when directly communicating with art and the subsequent creative interpretation in the process of drawing, which is the purpose of the research, we described

\footnotetext{
${ }^{1}$ Trakia University - Stara Zagora, Faculty of Education, Stara Zagora, Bulgaria, ani_zlateva@yahoo.com

2 Trakia University - Stara Zagora, Faculty of Education, Stara Zagora, Bulgaria, ktineva@abv.bg
} 
the results of the two stages: in the first stage we represented the results of 6 to 7 year-old-children's perception of art, and in the second stage we show the results from the children's creative activity as a result of the visual stimulation when communicating with pieces of art. We have tried to establish a connection between the processes of perceiving artworks and the active participation in the processes of reproducing them, with a certain degree of imagination involved

\section{Pedagogical aspects of communication with art and creative dynamics}

There are pieces of art in the exhibition hall at the city gallery in Stara Zagora belonging to a genre that children are familiar with - city, architectural and village landscapes. These are works of art created by some classic Bulgarian artists like Stanyu Stamatov (1886-1963), Dimitur Gyudzhenov (1891-1979), Miladin Lazarov (1894-1985), Zlatyu Boyadzhiev (1903-1976), Dimitur Karadzhov (1907-2000), Konstantin Tringov (1907-1981), Todor Kalpakchiev (1914-1984), Dimitur Hinkov (1904-1988), Dimitur Chehlarov (1933-2010), Ivan Popchev (1941-1994), Yanaki Kavrukov (19452002) and others.

These artists created their paintings adhering to the classic tendencies for that period (the second half of the $20^{\text {th }}$ century) - paintings with elements of modernism, decorative and associativelymetaphorical thinking. Every painting manifests the richness of creative decisions in stylish-plastic aspect.

The subject "the street" shows the different perspectives and points of view of the artists. It can be seen as a visual image representing a place for meetings, walks, work, embodying emotional and aesthetic experiences, offering associations with well-known places, bringing nostalgia for the past, for folklore or national history, or offering complicated metaphysical feeling.

The canvases acquaint children with the diversity of compositional preferences of individual authors. Within them the story narrative occupies an important place. It is present in most paintings and is emphasised by the presence of human figures and details in many compositions. In addition to the mere educational role of viewing the exhibition, an accent is put on the diversity of classical painting techniques and colourful solutions.

On the subject regarding the theoretical part of the communication with visual arts and the development of visual perceptions for different age groups in a museum environment, several names could be pointed out, such as those of Yuriy Protopopov, Frangoise Barbe-Gall, Eilean HooperGreenhill and others.

Yuriy Protopopov makes a full overview of the pedagogical practices as concerning the Russian and global experiences (Protopopov, 2013). The research and practice of Eilean Hooper-Greenhill reflect the British experience of education in art galleries, working with different audiences and present aspects of contemporary museology, while analysing them very thoroughly in theoretical, analytical and empirical aspects (Hooper-Greenhill, 2007).

The current research incorporates some ideas from the book by Frangoise Barbe-Gall "How to talk to children about art", in which the specific parameters regarding perceptions at early childhood age are being tracked (Barbe-Gall, 2002). The ideas of the author are based on research focusing on the questions of children's perceptions, creativity and development. The author offers an untraditional and free interactive approach to acquainting children with pieces of art in the stages of early communication with it, which is a good basis for the pedagogical experiment. Barbe-Gall also outlines the bottom borderline for perceiving fine arts which is 5 years of age and coincides with stages of development of art activities and visual perception, researched by notable names such as H. Read, C. Golumb, A. Wright and other specialists in the pedagogy of fine arts and psychology (Read, 1958, Golumb, 2004, Wright, 2001). The main aim when communicating with pieces of art in a gallery environment is the creation of positive attitudes towards art, which Barbe-Gall considers very important for activating perceptions. Clinging to the knowledge of children's perceptions when communicating with pieces of art, the group of children that participated in the research were emotionally directed first to observation and perception, and afterwards they are were motivated to get actively involved in creative art activities in the art gallery halls.

When perceiving the exhibited pieces of art children gradually introduce themselves to the subject by means of free observation of the pieces of art in the exhibition in the form of a game. In the art gallery 
halls children were carefully guided to every painting of the exhibition, as they were stimulated towards active communication and description while observing and perceiving.

Description of the works of art was related to children's expression of their initial impressions and perceptions. Children were encouraged to reveal their emotional co-experience of the pieces of art they were looking at. They were then gradually guided to discover different elements of the compositional structure, the depicted objects, as well as to find out emotional states, colours, forms, seasons, time of the day and other important compositional and formal-plastic signs of the artworks.

The process was complemented with achieving integrated pedagogical connections and through communication with the canvases from the exhibition, the aim was to develop their competences in different areas of knowledge.

Three important stages in the creative interpretation can be outlined, connected to the activation of children's imagination:

- Getting familiar with the interpretation of reality of individual authors, while emphasizing the specifics of imagination, knowledge and fantasy of the artist.

- Becoming acquainted with different creative interpretations of the subject and the basic moments and elements of the compositions and perceiving the artistic-plastic side of the paintings.

- Specifics, observing and analysing children's imagination which combines the complicated parts of the creative interpretation following pedagogical guidance and communication with art.



During the interactive pedagogical process children showed a very high level of participation and engagement with the subject while observing the artworks. Participants in the research were able to easily perceive realistic, as well as more decorative, abstract and surrealistic compositions and were capable of better comprehending the artistic aspects of the creative imagination and fantasy.

Of all the children who participated in the activity, 95\% demonstrated knowledge in the genre specifics, and they could distinguish the natural from the city landscape. The same percentage of children were able to easily discover the main elements of the compositions - trees, houses, people, animals, vehicles, clothing, etc. and they demonstrated a good knowledge of different colours, as they easily pointed to cleaner and brighter colours. At the same time as few as $32 \%$ of the children could distinguish mixed colours and were familiar with the colour shades. Over $65 \%$ reacted by recognising the seasons of the year, the plot of the paintings and can relate them to well-known short stories. Almost 40\% made free associations with their family, familiar places, the street they live on, and so 
on. Only $3.5 \%$ made a genuine attempt at finding a connection between the objects from the painting, the title of the painting, and the author.

At this age (6 to 7) children's initial attention is directed towards different objects from the composition and their details. They have difficulties perceiving the whole composition and the plot in the artworks. Children can understand more easily emotion, storytelling, and messages in the pieces of art with active pedagogical interaction while observing and perceiving the paintings.

These 6 to 7 year-old participants in the research reacted differently to every artwork in the exhibition. They showed much bigger interest in some of the paintings. Children preferred paintings which included well-known objects. In most cases their attention was attracted by the presence of human figures, familiar buildings, streets and different vehicles from the past and modernity. They were interested in the contemporary city landscape and reacted to the representation of different seasons, making steps towards more associative thinking. The children were attracted by bright colours, decorative and realistic compositions, with elements of modernism. The visual stimulation of children's imagination significantly influenced their creative decisions and interpretations while drawing.

During the stage of creative dynamics, our research on the manifestation of children's imagination and interpretation at this early age was based on the ideas of Lev Vygotsky from the 1960s. He states that children's imagination is "highly complicated in its composition process" in his book "Imagination and creativity of the child" (Vygotsky, 1982). Other authors, such as H. Read, C. Golumb and A. Wright share similar views concerning the abilities to influence the creative process. In their research they emphasized a series of different stimulations - mostly visual (Read, 1958, Golumb, 2004, Wright, 2001).

Vygotsky points out the psychological sides of the problem as he examines the genesis and specification of creativity, pointing out that for the development of children's visual perceptions, the "outside and inside perceptions", which the child gathers while growing up, are crucial.

To what extent does the direct contact with art in a gallery environment influence the creative process is a subject that has not been well studied so far. If we use the specifics of children's perceptions described by Vygotsky we could stimulate their creativity. He outlines two important stages of perception - "dissociation and association of the accumulated impressions" connected with the development of the creative abilities of children. According to him dissociation is important for the "future activity of fantasy" and develops "abstract thinking", whereas the following "combination of dissociation and amended elements" form children's associative thinking (Vygotsky, 1982).

In the next stage of the research, children started drawing once they had seen a demonstration of the art technique, accompanied with a description of the depicted objects and their construction, possible colour combinations and their impact, the compositional building of objects and the influence of the painting.

The drawings children created were under the influence of the subject "the street". In the drawings the following didactical qualities were analysed referring to: being consistent with the subject; the depicted objects - their number and diversity; compositional completeness and impact on the viewer. The most important part of the analysis regards the artistic and emotional impact of the artworks on the children.

Of all the participants, $94.7 \%$ created drawings on the same subject as the one from the exhibition "the street". This explains the high percentage of children (77.8\%) who included some of the objects they most often observed in the paintings from the exhibition - buildings, churches, trees. $55.6 \%$ of the children "literally" depicted the street as a specific object, and not as an object that should be understood as such.

What we find interesting is the high percentage of children who depicted space in a way different from the two-dimensional representation of reality with the means of the "frizz composition", which is typical for that age group. As Golumb notes "child's drawings exhibit very clearly the two-dimensional character of the graphic medium; that is, the near-flatness of the figures. Since the many-sidedness of objects in reality presents a formidable problem of translation into the two-dimensional medium, graphic representation necessitates a selection among possible views and aspects of the object" (Golumb, 2004). This makes the $66.7 \%$ of drawings where space is represented as an attempt to 
include the third dimension even more astonishing. With regard to composition, approximately $40 \%$ of the children positioned their objects differently compared to the linear alignment of the "frizz composition". Along with the evident interest in representing the third dimension, a significantly large percentage of children (23\%) offered some non-traditional compositional decisions, which differed from the linear placement of objects characteristic for this age group. When evaluating the use of colour in the drawings on the subject "the street", a strong correlation is observed between the colours used by children and the ones used in the artworks from the exhibition.

Nikolay Gyulchev points out that colour is one of the main creative means of expression in art and an important tool in children's artistic creativity based on the nature of visual perceptions. Because of this, he views colour as one of the main components of the artistic image (Gyulchev, 2003). It is difficult to estimate the exact percentage of children who chose the colours of their drawings under the influence of what they had seen in the exhibition, because the "chronology of the colours children at pre-school age use is directly linked to the formation of the needed abilities for colourful building of the composition" (Gyulchev, 2003). We can say with confidence, however, that all $100 \%$ of the drawings created by children in the art gallery demonstrate colour completeness, based on the fact that they all lack white spots. In $83.4 \%$ of the drawings, children showed a tendency to use colour contrasts. This contrast is usually represented as a choice of contrasting colours between the objects and the background. All children used the technique according to the instructions they had been given and they managed to achieve a high level of emotional impact in their drawings.

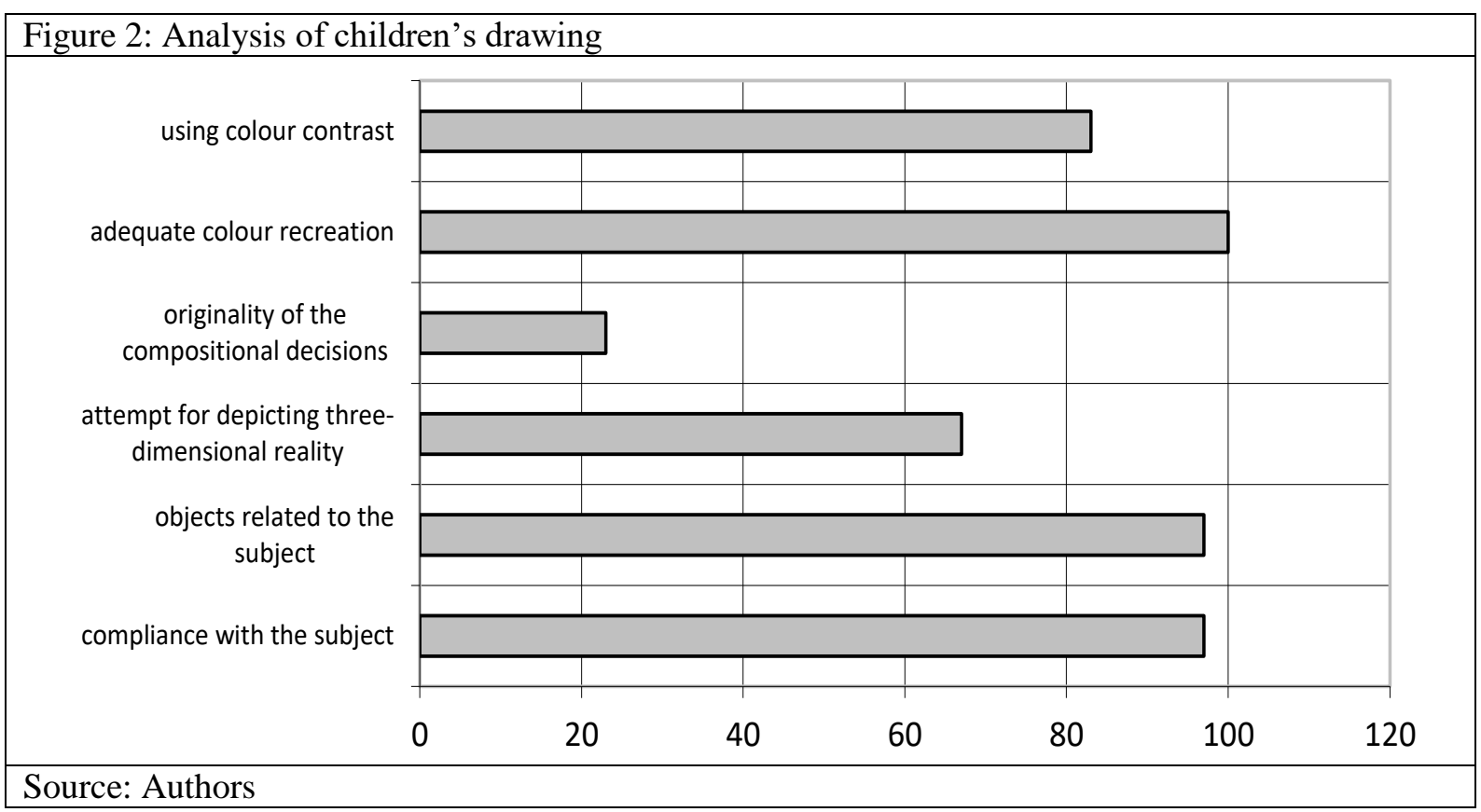

When comparing the results from the two stages of the research, we should emphasize the high level of compliance between the knowledge of the genre specifics of the artworks during the stage of perception and the corresponding high percentage of children who considered drawing on the set subject. The same correlation is evident when children recognize the main elements in the landscapes in the perceived artworks and subsequently depict objects native to the subject and the genre.

Distinguishing the main and complementary colour correlates with the adequacy of the colour compliance in the recreated drawings on the subject "the street". We can see an important link in the children's ability to recognize seasonal weather characteristics in the perceived artworks due to their existing knowledge of colour contrast. Using colour as a means of expression for recreating sunny, warm, cold, cloudy weather, night-time or morning-time turns out to be close and accessible for 6-7 year-old children.

\section{Conclusion}

In conclusion, it can be argued that opportunities for communication with and creative interpretation of pieces of art in an early childhood age need to become the focus of more thorough research. It is 
important to track the level of influence of the direct contact with artworks on the cognitive and creative aspects of children's development.

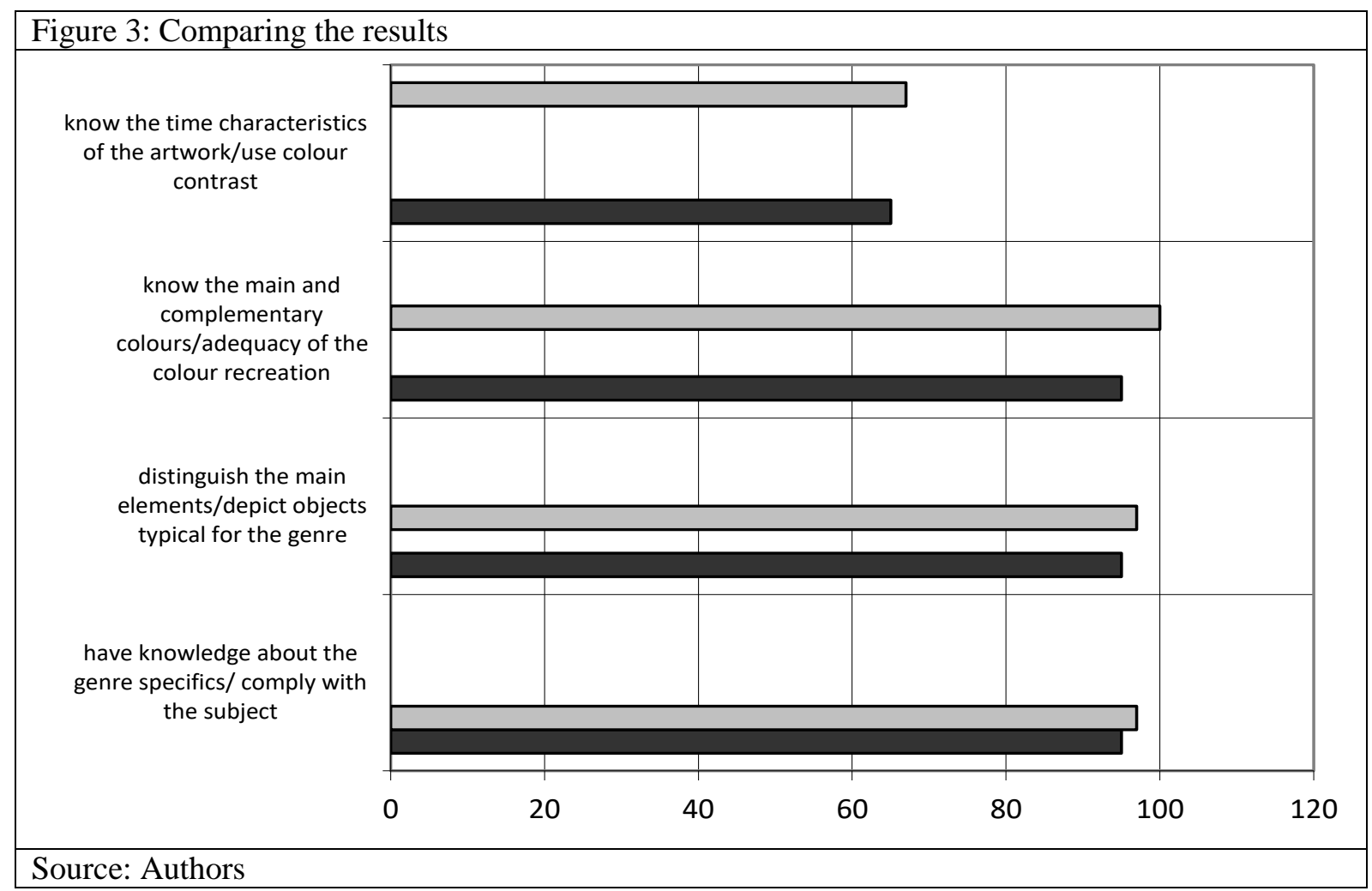

Researching the impact of visual stimulation on the quality of the original artworks of 6-7 year-old children helps to increase the abilities for developing children's cognitive and creative activity. Enhancing children's individual qualities in the process of creative interpretation is strongly related to the process of perceiving the original artworks in their natural gallery environment.

The role of the informal gallery environment is important for the achieved results because it suggests much more intense visual stimulation and enforces the desire for interactive engagement of children in the creative pedagogical process. What remains essential is the emotional impact of the original pieces of art with regard to children's aesthetic experiences.

The strong emotional reaction of children at the pre-school age influences their willingness to actively communicate and analyse artworks, as well as their eagerness to be involved in the process of recreating them. The level of emotional impact is additionally confirmed from the results of a followup survey, in which $56 \%$ of the participants declare their desire to become artists.

\section{References}

Barbe-Gall, Françoise.(2002) Comment parler d'art aux enfants. Paris: Societe nouvelle Adam Biro, 20.

Eilean Hooper-Greenhill. (2007) Museum and Education. Purpose, Pedagogy, Performance. NY: Routledge.

Golomb, C. (2004). The child's creation of a pictorial world (2nd ed.). NY: Psychology press, 101.

Gyulchev, N. (2003). Kompozicionnite umenia v hudozhestveno-izobrazitelnata deynost na decata ot preduchilishtna vuzrast. Pedagogicheski almanah, 11. [The Compositional Skills in the Artistic and Pictorial Activity of the Pre-school Child], 11, 91115, 105. Retrieved from http://journals.uni-vt.bg/almanac/eng/vol11/iss1/8

Protopopov, Yuriy. (2013) Features of the Development of Artistic Perception in the Museum. Pedagogy of art, 4, 1-31. Retrieved from http://www.art-education.ru/electronic-journal/osobennosti-razvitiya-hudozhestvennogo-vospriyatiya-vusloviyah-muzeya

Rodari, Dz. (2015) Grammar of Fantasy. Sofia: Siela. (Original work published 1973) Rodari, Dz. (2015) Gramatika na fantaziata. Sofia: Siela.

Read, H. (1958) Education through art. London: Faber and Faber.

Vygotsky, L. (1982) Vuobrazhenie i tvorchestvo na deteto. Nauka i izkustvo, Sofia. [Imagination and Creativity of the Children. Sofia: Science and Art. (Original work published in Moscow 1967)], 33, 34, $38 .$.

Vygotsky, L. (1978) Psihologia na izkusvoto. Nauka i izkustvo. Sofia. [Psychology of Art. Sofia: Science and Art. (Original work published in Rostov: Feniks 1998)]

Wright, A. (2001) Art and Crafts with Children. NY: Oxford University Press. 